\title{
Die Kinder im Blickpunkt der Osteopathie
}

\author{
Jürgen Griesinger
}

Mehr als 1000 Teilnehmer aus verschiedenen Ländern waren zum internationalen Kongress der Osteopathie Schule Deutschland (OSD) in Berlin angereist. Die mittlerweile 12. Auflage der 3-tägigen Veranstaltung stand unter dem Motto „Pädiatrie und Osteopathie“.

Wie in den Vorjahren läutete der „Tag der Forschung des Osteopathic Research Instituts“ den Kongress einen Tag vor dessen Eröffnung ein, über 120 Teilnehmer waren dabei.

Drei Tage lang, vom 20.-22. November 2015, drehte sich anschließend im wissenschaftlichen Bildungszentrum Urania im Zentrum von Berlin alles um die Kinderheilkunde in der Osteopathie. Die ausrichtende Osteopathie Schule Deutschland (OSD) bot 32 renommierte Referenten aus aller Welt auf, die in ihren Vorträgen die unterschiedlichen Bereiche der Kinderosteopathie behandelten. Da alle Vorträge durch Dolmetscher übersetzt wurden, konnte jeder den Rednern problemlos folgen. In anschließenden 26 Workshops wurde das zuvor Gehörte vertieft und praktisch umgesetzt ( $\triangleright$ Abb. 1).

\section{Weites Feld der pådiatrischen Osteopathie}

Die diagnostischen und therapeutischen Möglichkeiten in der Kinderosteopathie erweitern sich ständig. Bei den zahlreichen Vorträgen konnten sich die Kongress-

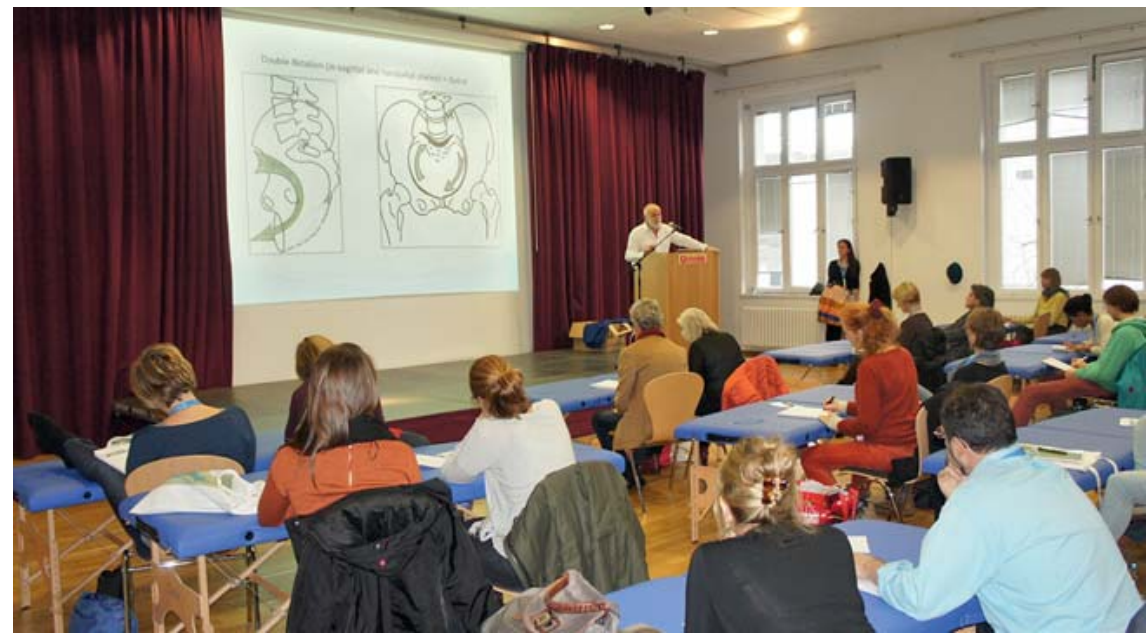

Abb. 1 Prof. Renzo Molinari gibt einen Workshop zu fetalen und geburtsbedingten Dysfunktionen. Foto: ๑ OSD

teilnehmer ein umfassendes Bild über den aktuellen Stand von Forschung und Wissen machen.

So ging es bspw. um die Auswirkung der intrauterinen Position auf die kindliche Entwicklung sowie um die Auswirkungen osteopathischer Behandlungen auf den Verdauungstrakt autistischer Kinder. Auch die Bedeutung der nonverbalen Kommunikation wurde behandelt und anhand der Wechselwirkung von Gestik und Mimik beschrieben, ein weiteres Thema war die kraniofasziale Behandlung von Strabismus. Und selbst für philosophische Gedanken war Platz: Der Ruf nach einer neuen Geburtskultur zielte ab auf die Verschmelzung von salutogenetischen und pathogenetischen Sichtweisen der Geburtshilfe.

\section{Aufbau und Pflege von Netzwerken}

Kongresse sollten mehr sein als der reine Informationstransfer und auch dem Aufbau und der Pflege interdisziplinärer und individueller Netzwerke dienen. Den passenden Rahmen dafür bot das auf den OSD-Kongressen traditionelle Gala-Dinner mit anschließender Party am Abend des 2. Veranstaltungstags.

Der nächste internationale Kongress der OSD behandelt das Thema „Trauma, ANS und Osteopathie“ und findet im November 2016 in Berlin statt.

\section{Online}

http://dx.doi.org/10.1055/s-0042-101089

Jürgen Griesinger, B. Sc., M. Sc.

Gutenbergstr. 5

55124 Mainz 